\title{
Infection Control Measures among Dental Professionals, Interns, and Students in Prosthodontic Department
}

\author{
Dixit $\mathrm{S}^{1}$, Dixit $\mathrm{PB}^{2}$, Pradhan $\mathrm{D}^{3}$, Gupta $\mathrm{S}^{4}$ \\ ${ }^{1}$ Associate Professor, Department of Prosthodontics and Maxillofacial Prosthetics, Kathmandu Medical College, \\ Duwakot, Bhaktapur, Nepal \\ ${ }^{2}$ Associate Professor, Department of Conservative Dentistry and Endodontics, Kathmandu Medical College, Duwakot, \\ Bhaktapur, Nepal \\ ${ }^{3}$ Assistant Professor, HOD, Department of Prosthodontics and Maxillofacial Prosthetics, Kathmandu Medical College, \\ Duwakot, Bhaktapur, Nepal \\ ${ }^{4}$ Assistant Professor, Department of Periodontics, Kathmandu Medical College, Duwakot, Bhaktapur, Nepal
}

\begin{abstract}
Introduction: Dental professionals frequently encounter infectious agents. Those not practicing proper infection control measures are at serious risk of infections. This study was conducted to assess knowledge, attitude, practice, and satisfaction of dental professionals regarding infection control guidelines to be followed in Prosthodontics.

Materials and Methods: This cross-sectional descriptive study was conducted from August to October 2020 in department of Prosthodontics, Kathmandu Medical College after obtaining ethical clearance and informed consent. Participants comprised of dental surgeons, interns, students, and faculties who were recruited by convenience sampling. The data on the questionnaire were collected via Google forms and analysed with Microsoft Excel. Descriptive statistics have been presented as frequency and percentages.

Results: A total of 154 questionnaires filled by 39 (25.32\%) males and 115 (74.68\%) females of mean age of $25.02 \pm 4.85$ years were analysed. Of all, $25(16.23 \%)$ had never had a lecture and $118(76.62 \%)$ had never had attended clinical demonstration or hands-on workshop on infection control. Only 129 (83.77\%) had received immunisation for hepatitis B. Most (144, 93.51\%) preferred mouth rinse before any procedure; $145(94.16 \%)$ agreed that disinfection is required between patients; and only $77(50 \%)$ of the participants washed their hands prior to wearing gloves. Majority $(123,79.97 \%)$ were not satisfied with their knowledge and performance.

Conclusions: Knowledge and attitude of participants regarding infection control was found adequate and positive, though lacking in practice. It is recommended that the infection control lectures and clinical demonstrations be increased in curriculum so that no future dentists are deprived of essential knowledge.
\end{abstract}

Key words: Attitude; Infection control; Knowledge; Nepal; Practice.

\section{Introduction}

$\mathrm{I}$ nfection, associated with various clinical, diagnostic, and therapeutic procedures

Conflict of Interest: No

\section{*Corresponding Author}

Dr. Siddharth Dixit

Associate Professor, Department of Prosthodontics and Maxillofacial Prosthetics, Kathmandu Medical College, Kathmandu, Nepal

Email: siddharthdxt@gmail.com is, one of the important causes of morbidity and mortality. ${ }^{1}$ Dental professionals in their practice, both laboratory works and clinical works, frequently encounter contaminated saliva, blood, aerosol, and other infectious agents. $^{2-4}$ Transmission of infections during prosthodontic and other dental procedures can take place via direct contact with saliva, blood, contaminated treatment water from dental units, droplets, and aerosols. It can also take place 
through indirect contact with contaminated surfaces and instruments. The, dental health care professionals, not practicing proper infection control measures, are putting their patients, coworkers as well as themselves at serious risk of infections with Hepatitis B, HIV and other infectious diseases. ${ }^{1,2,5-7}$ Hence this study was conducted with an aim to assess the knowledge, attitude, practice, and satisfaction of dental professionals, interns, and students regarding various infection control guidelines to be followed in the department of Prosthodontics.

\section{Materials and Methods}

This cross-sectional descriptive study was conducted from August to October 2020 in the department of Prosthodontics, Kathmandu Medical College, Duwakot, Bhaktapur, Nepal. Ethical clearance was obtained from the institutional review committee (IRC) before commencing the study. An informed consent was obtained from the participants before they were allowed in the questionnaire section. The students (from second, third, fourth, and final year), dental interns, dental surgeons and faculties of bachelor of dental surgery (BDS) programme were invited to participate in the study. Those students who had not been posted in the department of Prosthodontics were excluded from the study.

The participants were recruited by convenience (non-probability) sampling method. A sample size of 132 was calculated using following formula:

$$
\begin{aligned}
\text { Sample Size } & =\frac{\frac{Z^{2 *} p(100-p)}{e^{2}}}{1+\frac{Z^{2} * p(100-p)}{e^{2} N}} \\
& =110
\end{aligned}
$$

Where Population size $(\mathrm{N})=212$; Confidence level $(\%)=95 ; \mathrm{p}=17.8 \%{ }^{7}$ with Margin of error (e) $=5 \%$
Adding $20 \%$ to the non-response rate, sample size of 132 was calculated. Data were collected electronically via Google Forms. Links to the forms were shared with all 212 from the sampling frame. The questionnaire consisted of three parts: i) informed consent, ii) demographic details, and iii) questions. Informed consent was mandatory before proceeding to the questionnaire section. Only after they had read and clicked on the informed consent page, they were allowed access to the demographics page. Then after they had to answer three questions on knowledge, three on attitude, nine questions on practice, and three questions on satisfaction. It took about seven minutes to fill the questionnaire. The data from Google forms were opened with Microsoft Excel and analysed. The descriptive statistics have been presented as frequency and percentages.

\section{Results}

The questionnaire link was shared with all 212 individuals of sampling frame, out of which a total of 170 questionnaires were filled (response rate $80.18 \%$ ), which were reduced to $\mathbf{1 5 4}$ for data analysis after discarding for errors.

Among the total 154 valid questionnaires analysed, there were 39 (25.32\%) male and 115 (74.68\%) female participants with mean age of $25.02 \pm 4.85$ years (minimum 19.67 years and maximum 43 years). The responses to questions on knowledge are presented in Table 1, attitude in Table 2, practice in Table 3 and satisfaction in Table 4 respectively. Most of the participants were students $(93,60.39 \%)$ as illustrated in Figure 1. The work experience of faculties and dental surgeon $(\mathrm{N}=38)$ was $4.99 \pm 5.54$ years ranging from a minimum of 0 years to maximum 18 years (Figure 2 ). 


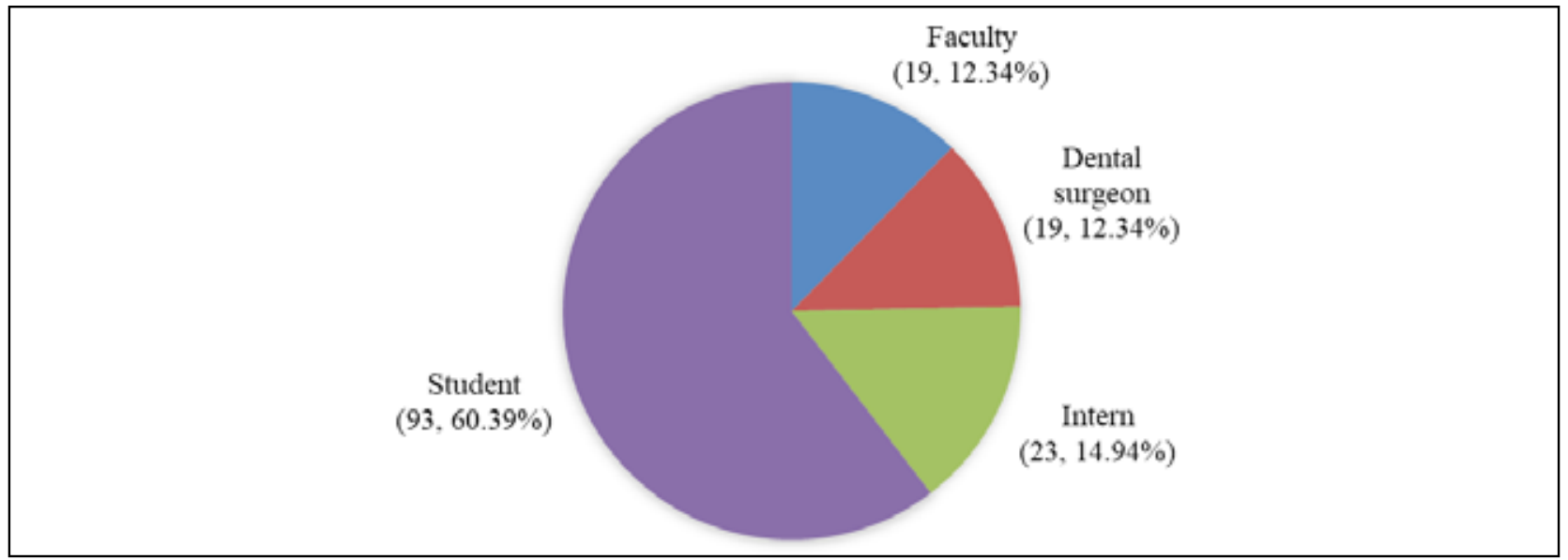

Figure 1: Distribution of participants, $n(\%)$.

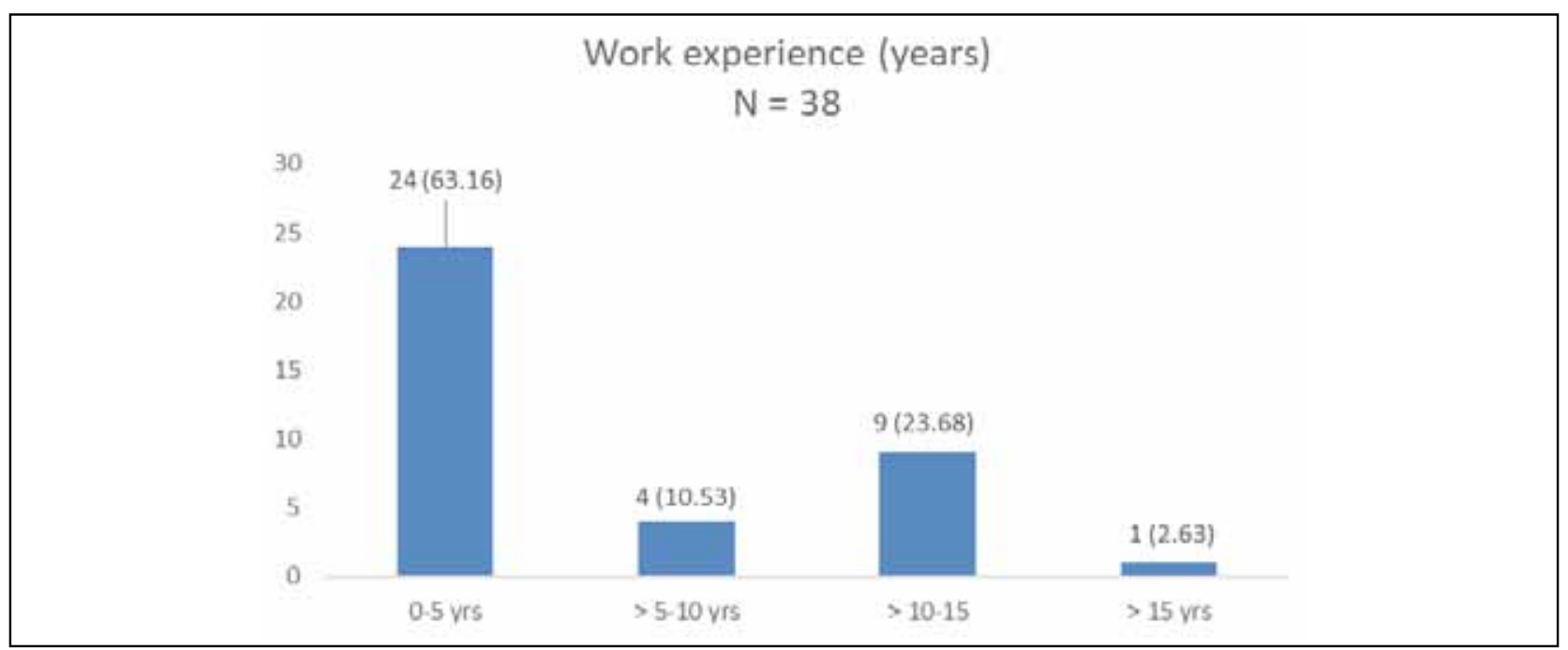

Figure 2: Work experience of the faculties and dental surgeons, $n(\%)$.

Table 1: Knowledge of infection control measures in prosthodontics, $\mathrm{n}(\%)$.

\begin{tabular}{|c|c|c|c|}
\hline Questions & Yes & No & Don't know \\
\hline $\begin{array}{l}\text { Ineffective sterilisation during clinical practice can transmit the } \\
\text { infection from one patient to another? }\end{array}$ & $151(98.05)$ & - & $3(1.95)$ \\
\hline \multicolumn{4}{|c|}{$\begin{array}{l}\text { Did you have didactic (theory) lectures about infection control during your undergraduate or internship } \\
\text { program? }\end{array}$} \\
\hline \multicolumn{2}{|l|}{ No, never had a lecture before } & \multicolumn{2}{|c|}{$25(16.23)$} \\
\hline \multicolumn{2}{|l|}{ Yes, only few lectures during undergraduate program } & \multicolumn{2}{|c|}{$109(70.78)$} \\
\hline \multicolumn{2}{|l|}{ Yes, 1 lecture weekly during one semester } & \multicolumn{2}{|c|}{$7(4.55)$} \\
\hline \multicolumn{2}{|l|}{ Yes, 1 lecture weekly during one academic year } & \multicolumn{2}{|c|}{$2(1.30)$} \\
\hline \multicolumn{2}{|l|}{ More than that } & \multicolumn{2}{|c|}{$11(7.14)$} \\
\hline \multicolumn{4}{|c|}{$\begin{array}{l}\text { Have you attended a clinical demonstration/ hands-on workshop about infection control during your } \\
\text { undergraduate program? }\end{array}$} \\
\hline \multicolumn{2}{|l|}{ No, never had a training before } & \multicolumn{2}{|c|}{$118(76.62)$} \\
\hline \multicolumn{2}{|l|}{ Yes, once during the undergraduate program } & \multicolumn{2}{|c|}{$25(16.23)$} \\
\hline \multicolumn{2}{|l|}{ Yes, twice during the undergraduate program } & \multicolumn{2}{|c|}{$6(3.90)$} \\
\hline \multicolumn{2}{|l|}{ Yes, every year } & \multicolumn{2}{|c|}{$5(3.25)$} \\
\hline
\end{tabular}


Table 2: Attitude towards infection control measures in prosthodontics, $\mathrm{n}(\%)$.

\begin{tabular}{|l|c|c|}
\hline Questions & Yes & No \\
\hline $\begin{array}{l}\text { Do you prefer oral mouth rinse before the commencement of any treatment } \\
\text { procedure? }\end{array}$ & $144(93.51)$ & $10(6.49)$ \\
\hline $\begin{array}{l}\text { Have you received the Hepatitis B Virus Immunisation Vaccine? } \\
\begin{array}{l}\text { Is the disinfection of the dental chair, clinic/department, and dental office/ } \\
\text { hospital required between patients? }\end{array}\end{array}$ & $129(83.77)$ & $25(16.23)$ \\
\hline
\end{tabular}

Table 3. Practice of infection control measures in prosthodontics, $\mathrm{n}(\%)$.

\begin{tabular}{|c|c|c|c|}
\hline Questions & Yes & No & Sometimes \\
\hline Do you wash your hands prior to wearing gloves? & $77(50)$ & $32(20.78)$ & $45(29.22)$ \\
\hline \multicolumn{4}{|c|}{ Do you regularly wear following barriers during dental procedures? } \\
\hline Gloves & $146(94.81)$ & $5(3.25)$ & $3(1.95)$ \\
\hline Change gloves between patients & $138(89.61)$ & $9(5.84)$ & $7(4.55)$ \\
\hline Face mask & $145(94.16)$ & $7(4.55)$ & $2(1.30)$ \\
\hline Change face mask between patients & $51(33.12)$ & $57(37.01)$ & $46(29.87)$ \\
\hline Protective glass/face shield & $55(35.71)$ & $81(52.60)$ & $18(11.69)$ \\
\hline Disinfect protective glass/face shield & $40(25.97)$ & $91(59.09)$ & $23(14.94)$ \\
\hline Protective gowns & $80(51.95)$ & $61(39.61)$ & $13(8.44)$ \\
\hline Change protective gowns between patients & $14(9.09)$ & $119(77.27)$ & $21(13.64)$ \\
\hline Surgical/head cap (cover) & $144(93.51)$ & $5(3.25)$ & $5(3.25)$ \\
\hline \multicolumn{4}{|c|}{ Do you (or your dental assistant) regularly disinfect the following items between patients? } \\
\hline Rubber bowl & $99(64.29)$ & $32(20.78)$ & $23(14.94)$ \\
\hline Alginate mixing spatula & $102(66.23)$ & $31(20.13)$ & $21(13.64)$ \\
\hline Face bow & $84(54.54)$ & $50(32.47)$ & $20(12.99)$ \\
\hline Shade guide & $80(51.95)$ & $54(35.06)$ & $20(12.99)$ \\
\hline $\begin{array}{l}\text { When taking primary (alginate) or final impression, do you } \\
\text { (or your dental assistant) apply plastic/rubber barrier or } \\
\text { apply disinfectant on impression gun between patients? }\end{array}$ & $70(45.45)$ & $56(36.36)$ & $28(18.18)$ \\
\hline $\begin{array}{l}\text { Do you rinse the impression under running water } \\
\text { immediately after being removed from patient's mouth? }\end{array}$ & $124(80.52)$ & $17(11.04)$ & $13(8.44)$ \\
\hline $\begin{array}{l}\text { Do you apply disinfectant on the impression after rinsing } \\
\text { with water? }\end{array}$ & $58(37.66)$ & $72(46.75)$ & $24(15.58)$ \\
\hline $\begin{array}{l}\text { When you apply disinfectant on the impression, do you also } \\
\text { apply it on the outer surfaces of the tray }\end{array}$ & $52(33.77)$ & $80(51.95)$ & $22(14.29)$ \\
\hline \multicolumn{4}{|c|}{ Do you regularly disinfect the following items before sending it to the dental laboratory? } \\
\hline Dental cast & $57(37.01)$ & $77(50)$ & $20(12.99)$ \\
\hline Denture prosthesis & $91(59.09)$ & $44(28.57)$ & $19(12.34)$ \\
\hline $\begin{array}{l}\text { Metal framework for removable or fixed prosthesis after } \\
\text { try-in }\end{array}$ & $87(56.49)$ & $47(30.52)$ & $20(12.99)$ \\
\hline Bite registration or wax rim & $73(47.40)$ & $61(39.61)$ & $20(12.99)$ \\
\hline Face bow and fork & $77(50)$ & $51(33.12)$ & $26(16.88)$ \\
\hline
\end{tabular}


Do you sterilise (autoclave) the following items before using it for a patient?

\begin{tabular}{|l|l|l|l|}
\hline Face bow fork & $95(61.69)$ & $41(26.62)$ & $18(11.69)$ \\
\hline Fox occlusal plane & $91(59.09)$ & $44(28.57)$ & $19(12.34)$ \\
\hline
\end{tabular}

Table 4: Satisfaction of infection control measures in prosthodontics, $\mathrm{n}(\%)$.

\begin{tabular}{|c|c|}
\hline Questions and Responses & n (\%) \\
\hline \multicolumn{2}{|c|}{ How do you evaluate your knowledge about infection control in the Prosthodontic clinic? } \\
\hline Very poor & $2(1.30)$ \\
\hline Poor & $20(12.99)$ \\
\hline Fair & $89(57.79)$ \\
\hline Good & $42(27.27)$ \\
\hline Very good & $1(0.65)$ \\
\hline \multicolumn{2}{|c|}{$\begin{array}{l}\text { How do you evaluate your implementation of infection control policy in your Prosthodontic/clinical } \\
\text { practice }\end{array}$} \\
\hline Very poor & $3(1.95)$ \\
\hline Poor & $25(16.23)$ \\
\hline Fair & $89(57.79)$ \\
\hline Good & $36(23.38)$ \\
\hline Very good & $1(0.65)$ \\
\hline \multicolumn{2}{|c|}{$\begin{array}{l}\text { Are you satisfied with your knowledge and your performance in infection control in your Prosthodontic } \\
\text { clinical practice? }\end{array}$} \\
\hline Yes & $31(20.13)$ \\
\hline No & $123(79.87)$ \\
\hline
\end{tabular}

\section{Discussion}

Dental professionals and students frequently encounter infectious agents in the form of saliva, blood, aerosol, etc., in their day to day practice. ${ }^{1-4}$ This is especially true for the prosthodontics procedures that are performed in hospital as well as laboratory setting. The contamination during prosthodontic and other dental procedures can take place through direct or indirect contact. A landmark study done by Mosley et al. stated that dentists were three times more likely to be infected with Hepatitis B than general population. ${ }^{6}$ Thus, following infection control measures at workplace is essential for reducing accidental exposure to various infectious agents. ${ }^{1,7}$ Those dental health professionals, not practicing proper infection control measures, are putting their patients, co- workers as well as their own health at serious risk of infections. Hence, infection control measure becomes an integral component for every procedure in dentistry, ${ }^{7}$ more so in the Prosthodontics because of its wide array of clinical and laboratory works. Assessment and improvement of compliance with standard infection control guidelines in prosthodontics clinic among dental professionals is very important and it should be started as early as possible.

To the question whether ineffective sterilisation during clinical practice can transmit the infection from one patient to another, the expected answer was $100 \%$ "Yes", however, only $98.05 \%$ agreed and $1.95 \%$ though a small percentage, are still not aware of the infection transmission. 
Under current BDS curriculum of Nepalese Universities, the lectures on infection control start as early as first year. In the department of Prosthodontics, students of second year have to apply the infection control measures in Prosthodontic laboratory whereas the fourth and final year students apply in the clinical setting. The students, interns, and dental professionals are restricted from wearing jewellery in the Prosthodontic department, must have short nails without any polish on. They also have to be immunised with hepatitis $B$ vaccination before joining the clinical setting. However, these guidelines are not always followed.

About lectures and clinical demonstration on infection control during undergraduate program and internship, $16.23 \%$ had never had a lecture and $76.62 \%$ had never attended clinical demonstration or hands-on workshop. This is lesser number of lectures and clinical demonstrations attended than that reported by Alshiddi et al. ${ }^{7}$ and Deogade et al. ${ }^{2}$ This shows that though the lectures and clinical demonstrations are often included in the curriculum of undergraduate program, it is not mandatory to attend. This way, vital information is being missed by the future dental professionals. It is recommended that the infection control lectures be increased in number or it should be made compulsory so that no future dentists are deprived of the essential knowledge.

When asked whether they preferred mouth rinse before any procedure, 93.51\% answered they did. This is lot more than the $58 \%$ in faculty and $48.2 \%$ in students reported by Alharbi et al. ${ }^{1}$ and $56.7 \%$ reported by Singh et al. ${ }^{3}$ Similarly, $94.16 \%$ agreed that disinfection of dental chair, clinic, and office is required between patients in accordance with previous study. ${ }^{1}$ Of all participants, $16.23 \%$ had not received immunisation for hepatitis B. This means they are not aware of the risk they are putting themselves into. This is higher proportion of dental health care professionals not immunised than reported previously., ${ }^{1,7}$

Regarding practice, only $50 \%$ of the participants washed their hands prior to wearing gloves. This is similar to study by Alharbi et al. ${ }^{1}$ but is lesser than that reported by Singh et al. (95.5\%). ${ }^{3}$ When asked about protective barriers, though majority wore gloves, face masks, and surgical caps during procedures, similar to previous studies ${ }^{1,2,7,8}$ not all wore protecting face shields or gowns, or changed gloves, face mask, or protective gowns between patients in contrast to the study done by Alharbi et al. ${ }^{1}$ The rubber bowl, spatula, face bow, and shade guide were regularly disinfected by most participants. However, few still did not practise those disinfection procedures which is in agreement with that reported by previous studies. ${ }^{1,2,7}$ The disinfection practice of these items should be monitored more closely for better adherence with recommended practice. Most of the participants did not disinfect various items such as dental cast, prosthesis, wax rims before sending them to laboratory for further work. This is in agreement with the results from Alshiddi et al. $^{7}$ and Deogade et al. ${ }^{2}$ studies. Again, despite different geographic locations, the disinfection practice is not at par.

When the participants were asked to evaluate their knowledge and implementation of infection control measures, most answered as $\operatorname{good}(42,27.27 \%)$ and fair $(89,57.79 \%)$. However, majority $(123,79.97 \%)$ were not satisfied with their knowledge or performance regarding the same in their practice and only $1(0.65 \%)$ evaluated his/her knowledge and implementation of infection control as very good. This is in agreement with Alshiddi et al. Ghimire et al. ${ }^{4}$

Dental education worldwide requires a high level of medical training, clinical skills, and knowledge of infection control. ${ }^{7}$ Most of the studies have shown that, though the dental faculty members and undergraduate students 
had good practice of the infection control guidelines, there is lack in the knowledge of infection control standards. ${ }^{1-5,7,8}$ Various suggested strategies to protect dental and other health workers include: i) implementation of standard precautions, ii) immunisation against infectious diseases of concern, iii) personal protective equipment, iv) accurate cleaning and disinfection of surfaces and equipment v) sterilisation of instruments and vi) proper techniques for handling sharp instruments and WHO recommended management of exposure. ${ }^{5}$ Because of lack of systematic health history database in a country like ours, the application of Standard Precautions to "all" patients is essential and recommended by for all dental procedures. $^{1,9}$

The students and interns are at the beginning of theircareerindentistry. So, this assessment would also increase their awareness or the lack of it with respect to infection control and sterilisation that should be followed in dental department as a whole and Prosthodontic specificallyAs demonstrated in various research, the chances of cross-contamination are more likely among dental students than more experienced dental surgeons or faculties. The students often do not seem to realise the gravity of risk of infectious disease they are being exposed to or they might be exposing their patients, colleagues, and other health professionals to. However, certain study has reported no significant difference in the knowledge of dental faculty members and students regarding infection control guidelines. ${ }^{1}$ Hence it becomes imperative that both the learners as well as teachers are aware of and always properly adhere to the infection control measures. The lack of comprehensive institutional guidelines and effort to teach infection control might also be one of the major factors if good infection control practice is not observed. Such factors may lead to the lack of adherence to infection control strategies which can have profound effect on the society. The elaborate University curriculum, though have the topic, it needs revisions from time to time with the updated infectious data.

The researchers believe that this study will motivate the participants in improving their knowledge and practice of better infection control measures. The result of the study has also provided valuable information to evaluate the adequacy of existing undergraduate dental curriculum with respect to infection control strategies.

The limitations of the study could be that it was a single-centre study with small sample size. No standard tool or scale was used to measure the knowledge, attitude, practice, and satisfaction parameters. The data was collected using selfadministered questionnaire that the participants may not have respond accurately. For accurate results, supervision of responders' practice should have been done.

\section{Conclusions}

Current study shows that though the knowledge and attitude of dental professionals and BDS students of KMC regarding infection control guidelines can be considered adequate and positive, the participants are not satisfied with their performance and there is a need to increase the adherence with standard infection control guidelines for the prevention of disease transmission and safer dental procedures.

\section{Acknowledgements}

We would like to acknowledge Kathmandu Medical College IRC, Dr. Sirjana Dahal and all the participants for their help, time, and cooperation.

\section{References}

1. Alharbi G, Shono N, Alballaa L, Aloufi A. Knowledge, attitude and compliance of infection control guidelines among dental faculty members and students in KSU. BMC oral health. 2019;19(1):7. [PubMed | DOI] 
2. Deogade SC, Suresan V, Galav A, Rathod J, Mantri SS, Patil SM. Awareness, knowledge, and attitude of dental students toward infection control in prosthodontic clinic of a dental school in India. Niger J Clin Pract. 2018;21(5):553-9. [PubMed | DOI]

3. Singh A, Purohit BM, Bhambal A, Saxena S, Singh A, Gupta A. Knowledge, attitudes, and practice regarding infection control measures among dental students in Central India. 2011;75(3):421-7. [PubMed]

4. Ghimire B, Chandra S. Awareness of infection control among dental students and interns. J Nepal Med Assoc. 2018;56(210):598-601. [PubMed]

5. Malhotra V, Kaura S, Sharma H. Knowledge, attitude and practices about hepatitis $\mathrm{B}$ and infection control measures among dental students in Patiala. J Dent Allied Sci. 2017;6(2):65-9. [Full Text]
6. Mosley JW, Edwards VM, Casey G, Redeker AG, White E. Hepatitis B virus infection in dentists. N Engl J Med. 1975;293(15):729-34. [PubMed | DOI]

7. Fahad Alshiddi I. Attitude and awareness of dental students and interns toward infection control measures in prosthodontic clinics. Dent Oral Craniofac Res. 2015;1(4):7-14. [Full Text]

8. Halboub ES, Al-Maweri SA, Al-Jamaei AA, Tarakji B, Al-Soneidar WA. Knowledge, attitudes, and practice of infection control among dental students at Sana'a University, Yemen. J Int Oral Health. 2015;7(5):15-9. [PubMed]

9. Kohn WG, Harte JA, Malvitz DM, Collins AS, Cleveland JL, Eklund KJ, et al. Guidelines for infection control in dental health care settings--2003. J Am Dent Assoc. 2004;135(1):33-47. [ PubMed | DOI] 